\title{
Preventing violent extremism through universal values in curriculum
}

\author{
P. T. M. Marope ${ }^{1}$
}

Published online: 9 November 2019

(C) UNESCO IBE 2019

The 2030 Agenda for Sustainable Development envisages "a world of universal respect for human rights and human dignity, the rule of law, justice, equality and non-discrimination" (United Nations 2015, p. 7). It places a strong emphasis on peaceful, just and inclusive societies, as an unprecedented opportunity to set the world on a sustainable course and to ensure a life of dignity for all. However, while the world is progressively embracing principles of equity, diversity, and tolerance, it remains deeply divided. An alarming number of serious instances of intolerance and discrimination-including acts of aggression, intimidation and coercion, and violence-have recently occurred in many parts of the world. A growing threat is posed by terrorism and violent extremism. With its increasing intensity and global spread, violent extremism activity threatens the enjoyment of human rights and fundamental freedoms and violates the universal standards of justice enshrined in the Universal Declaration of Human Rights and other agreements. Its effects can spill over regionally, nationally, and globally, impacting economic performance, creating pressures in the form of displaced populations, both internally and as refugees, and diverting resources toward containing violence and thus away from development. This, in turn, "reduces the sustainability of economic growth, weakens social cohesion and security, encourages inequitable access to and use of global commons, undermines our democracies, and cripples our hopes for sustainable development and peaceful societies" (Mohammed 2015, p. 1). In the long run, all such activities undermine development. Identifying and understanding the underlying grievances or causes that lead to violent extremism, and taking all appropriate measures to prevent hatred, intolerance and violent extremism, are complex and challenging processes.

P. T. M. Marope

ibe.prospects@unesco.org

1 UNESCO International Bureau of Education, Geneva, Switzerland 


\section{Education and violent extremism}

Addressing these issues requires a unified response and an integrated agenda that looks at the problem across the social, economic, cultural, and environmental dimensions, including access to education, healthcare, and resources. Central to these efforts is education. Promoting equitable, inclusive, and quality education is "the way to disarm the processes that may lead to violent extremism, by undermining prejudice, by fighting ignorance and indifference" (Former UNESCO Director-General Irina Bokova, at the 18th Commonwealth Lecture in London, 25 February 2016). The process, which requires concerted action at all levels, from local to national, and regional to global, involves engaging children, youth, and adults in strengthening the narrative of a single humanity and empowering them as agents of change.

Against this context, education and learning need to be thought of in far less instrumental terms. They also determine a nation's social fabric, by shaping people's dispositions, attitudes, and ethics, and thus building (or not) inclusive, tolerant, diverse societies.

All these facts point to the urgent need to return to fundamental questions about the aims and purposes of education and to a more holistic, integrated, and humanistic vision of learning, which conveys values that will help develop more just and inclusive societies. Values, dialogue, participation, empowerment, and peace-building are critical drivers of social inclusion, an imperative of development.

While many people recognize the relationships between education, inclusion, equality, and peace-building, what is less often recognized is the role curriculum can play in preventing intolerance, hatred, prejudice, and extremism-and it is not used to its full potential.

Curriculum can and should contribute positively to reducing intolerance and extremism. Curriculum can promote knowledge about, and understanding of, different cultures. Curriculum can also equip learners of all ages with those values, knowledge, and skills that are based on, and instill respect for, human rights and social justice, and that empower learners to be responsible global citizens. Curriculum can contribute to all the dimensions involved in building equitable, just, and tolerant societies, among them conflict prevention, social transformation, civic engagement, and economic progress. It can address underlying inequities that fuel conflict, and it can empower disenfranchised groups, inform civic education, and shape democratic participation and decision-making.

\section{The IBE's initiative}

In 2016, the IBE launched an initiative to prevent violent extremism through the mainstreaming of universal values in curricula. This initiative notes that the global vocabulary and dialogue on addressing intolerance, violence, and extremism have focused more on diversity than on similarities. While efforts to acknowledge and celebrate our differences are critical, they remain incomplete: we cannot fully appreciate our differences unless we recognize and embrace our common humanity. 
The IBE strongly believes that there is more that holds us together than what separates us and seeks to use curricula to highlight the universality of values that hold humanity together.

At the heart of this position lies an understanding of the remarkable diversity of our world, coupled with a keen appreciation of the shared humanity that unites us. Our working assumption is that acknowledging and even celebrating the universality of human values is the first step toward living together in unity and harmony.

The IBE's response builds on UNESCO's raison d'être: to promote international understanding, cooperation, peace, and respect for human rights and fundamental freedoms. It also builds on the third pillar of learning, underlined in the UNESCO Delors report: "learning to live together" (Delors et al. 1996). Learning to live together begins with a "qualified universalism of human values", a stance that acknowledges the dominance of shared human values, tempered with the contextual particularity of some values.

The IBE proposes a hybrid approach that is both philosophically based and educationally pragmatic in recognizing both the universality and the particularities of values. This hybrid position may be referred to as 'qualified universality'. While acknowledging that a range of different interpretations, tensions, and assumptions confront the notion of universal values, the IBE maintains that a hybrid approach of qualified universality is possible, based on philosophical and socio-psychological arguments about common values across cultures. This qualified universality embraces cultural plurality, while recognizing that common values are paramount.

Diversity, pluralism, and personal freedom are not incompatible with the recognition of universal values. On the contrary, universal values are actually required if we are to protect diversity, pluralism, and freedom, "treating each human being as an agent and an end" (Nussbaum 1999, p. 63). The IBE argues for ongoing, dynamic processes of deliberation on how such qualified universality can take place at multiple levels of education and learning-e.g., from national curriculum to schools, from formal to informal curricula, etc.-as well as in cross-national forums such as those that the IBE and UNESCO, more generally, facilitate.

One way to address these concerns together is to generate a list of universal values that is sufficiently flexible to enable us to do justice to our diversity. As our understanding of qualified universality continues to evolve, it would be unwise to be sidetracked for too long by theoretical debates about the existence of universal values. Rather, we should move forward with deliberative processes that identify common values across cultures, as well as their variations, mindful that we must protect the particularities underpinned by the human rights standards.

Curricula are important avenues for promoting a hybrid approach that accommodates both the universality and the particularity of values. They enable learners to reflect on their own understanding of the universality of some values, while developing their ability to examine related issues, leading them to be more socially conscious of the culture they are personally engaged in.

The IBE's work on universal values is naturally connected to UNESCO's Global Citizenship Education (GCED) initiative, one of UNESCO's strategic areas of work, a target of the global Education 2030 Agenda, and underlined in the Sustainable Development Goal (SDG) 4.7:

By 2030, ensure that all learners acquire the knowledge and skills needed to promote sustainable development, including, among others, through education for sustainable development and sustainable lifestyles, human rights, gender equality, promotion of a 
culture of peace and non-violence, global citizenship and appreciation of cultural diversity and of culture's contribution to sustainable development.

The GCED, which aims to build values, soft skills, and attitudes among learners to promote social transformation and facilitate international cooperation, can serve as a framework for putting universal values into operation, and for directly engaging with many of the related issues, such as social justice, human rights, inclusion, diversity, gender equality, environmental sustainability, etc. (UNESCO 2017)

The IBE is leading a complex process of articulating and endorsing the universal values that need to be promoted and taught, to prevent violent extremism. This process requires concerted action at all levels, from local to national, and regional to global. It involves participating in multicultural and interfaith dialogue, and engaging youth in strengthening the narrative of a single humanity and empowering them as agents of change. Mainstreaming universal values in curricula is the first operational instrument through which education systems can address violent extremism.

\section{About this special issue}

We are all connected, in the words of Martin Luther King, Jr. (1967), "in a single garment of destiny", and we need to learn to live and work together, to improve the human condition. This simple yet so powerful idea is the unifying thread throughout the articles published in this double special issue on preventing violent extremism.

When we invited Conrad Hughes to guest edit it, we knew that the final product would be special indeed. He is not only a globally acknowledged thinker and prolific author, whose work addresses prejudice in education and global challenges for the 21st century education. An IBE Senior Fellow, with PhDs in education and literature, Conrad Hughes also comes to the subject as an educator and school administrator. Educated in South Africa and England, he has worked in schools in Switzerland, France, India, and the Netherlands. He is now Campus and Secondary Principal at the International School of Geneva, La Grande Boissière, the oldest international school in the world, which has learners from over 130 different cultures, and strives to make the world a better, more peaceful, openminded place through education.

In this special issue, Conrad Hughes brings together some of the leading voices for the worldwide effort to prevent violent extremism: philosopher A. C. Grayling; peace activist and proponent of non-violence Ali Abu Awwad; human rights expert and UNESCO Chair in Human Rights and Higher Education Felisa L. Tibbitts; professor and Holocaust education researcher Doyle Stevick; neuroscientist Laura Ligouri; and philosophical practitioner Natalie M. Fletcher. Their exceptional contributions identify some of the drivers of violent extremism and argue for the urgent need to reflect on our commonalities, to challenge ourselves to restore a sense of agency in building a collective future.

\section{References}

Delors, J., et al. (1996). Learning. The treasure within. Paris: UNESCO.

King, Martin Luther Jr. (1967). A Christmas sermon on peace. Massey Lecture 5, Ebeneezer Baptist Church, Canada. Public Radio Exchange (PRE). https://exchange.prx.org/series/31037-martin-luthe r-king-jr-massey-lectures

Mohammed, A. J. (2015). Deepening income inequality. Geneva: World Economic Forum. 
Nussbaum, M. (1999). In defense of universal values. The Fifth Annual Hesburgh Lectures on Ethics and Public Policy. Notre Dame, IN: University of Notre Dame. http://philosophy.uchicago.edu/faculty/files/ nussbaum/In\%20Defense\%20of\%20Universal\%20Values.pdf

UNESCO (2017). Global citizenship education. https://en.unesco.org/themes/gced.

United Nations (2015). Transforming our world: The 2030 Agenda for Sustainable Development. Resolution adopted by the General Assembly on 25 September 2015. New York, NY: United Nations.

Publisher's Note Springer Nature remains neutral with regard to jurisdictional claims in published maps and institutional affiliations. 